\title{
Features of the bioecological state of water bodies in the Leningrad region and de- eutrophication measures
}

\author{
Viktor Sboichakov ${ }^{1, *}$, Dmitriy Kulev ${ }^{1}$, Olga Reshetnikova $^{1}$, Tatiana Osipova ${ }^{1}$ and Ludmila \\ Kovaleva ${ }^{1}$ \\ ${ }^{1}$ A. S. Pushkin Leningrad State University (Luga branch), Volodarskogo str., 52a, Luga of the \\ Leningrad region, 188230, Russia
}

\begin{abstract}
Natural waters are polluted by sewage, industrial and transport waste leads to a decrease the oxygen content in the water and the disappearance of valuable fish species. As a result, the eutrophy of the reservoir develops - the saturation of reservoirs with biogenic elements, accompanied by an increase in the biological productivity of water basins. The purpose of the work was to study the bioecological state of water basins in the Luga district of the Leningrad region, the prospects for deeutrophication. The monitoring data of water bodies were studied and factors influencing the bioecological state of water bodies were considered. Physicochemical, sanitary and microbiological, parasitological and toxicological research methods were used in the work. Objects of research: the rivers Obla and Svinechnaya; lakes Toloni and Omchino. All this is a very unfavorable factor and indicates strong water pollution. To combat the eutrophication of water bodies, preventive and regulatory measures are used. A promising prevention of eutrophication is a biotechnological method, including the cultivation of plants in the coastal zone, breeding of herbivorous fish, the use of the method of algolization (introduction of a chlorella suspension).
\end{abstract}

\section{Introduction}

The deterioration of the quality of natural waters and the state of water systems as a result of increased anthropogenic activity has become an urgent problem of our time. Pollution of natural waters occurs with sewage, industrial and transport waste, chemical and organic fertilizers, especially affected by low-flow lakes, in which cyanobacteria (bluegreen algae) begin to multiply intensively. In turn, this leads to a decrease in the oxygen content in the water and the disappearance of valuable fish species. In the final stage, eutrophy of the reservoir develops - saturation of reservoirs with biogenic elements, accompanied by an increase in the biological productivity of water basins $\square 1,2,3 \square$. This will eventually lead to the disappearance of the lake, which will later become a swamp.

About a third of the total mass of pollutants is introduced into water sources with surface and storm runoff from the territories of sanitary places, agricultural facilities and

\footnotetext{
* Corresponding author: sboich.viktor@yandex.ru
} 
land, which affects the seasonal, during the spring flood, deterioration of the quality of drinking water. Sources of pollution are also associated with human activities: transportation, processing and use of oil as fuel and industrial raw materials. Among the products of industrial production, toxic synthetic substances taking a special place in terms of their negative impact on the aquatic environment and living organisms.

Pollution of water bodies leads to a reduction in food resources due to the inability to consume fish, fish products that can be contaminated with various toxic chemicals: heavy metals, organochlorine pesticides, polychlorinated biphenyls. Polluted waters of reservoirs can not be used for irrigation of agricultural land, they also can not be used in animal husbandry and poultry farming.

Sanitary and epidemiological surveillance services constantly note high pollution of surface water. Long-term observations of the dynamics of surface water quality reveal a tendency to increase the number of reservoirs with a high level of pollution. All this fully applies to the southern districts of the Leningrad Region, in particular, the Luzhsky district, where there are many reservoirs. The quality of water in the Luga River, as well as in wells and springs, where most of the region's population takes water for drinking use, is a topical issue for residents of the Luga district. Discharges of sewage from towns and cities, flushes from fields where excessive amounts of nitrogen fertilizers are used as a result of improper management, storage of manure on farms, cesspools - all this creates a biogenic load on natural waters. Excessive intake of nutrients (mainly nitrogen and phosphorus) leads to eutrophication-reservoirs begin to "bloom", water quality deteriorates.

The term eutrophication should be understood as an excess intake of organic and mineral substances into water bodies.

Climate change exacerbates the problem - the number of flooding and flooding of territories is growing, which increases the risks of flushing from the territories and the flow of nitrogen-containing substances into water bodies, which have an adverse effect on the human body $\square 4 \square$. In recent decades, due to the increased anthropogenic impact, the intensity of eutrophication has increased dramatically. This is due to the entry into the reservoirs of a significant amount of nutrients-nitrogen, phosphorus and other elements in the form of fertilizers, detergents, animal waste, atmospheric aerosols, etc. The processes of anthropogenic eutrophication cover the worlds large lakes, including Lake Ladoga. In the Luga region this primarily refers to the Omchino and Toloni lakes.

The aim of the work was to study the bioecological state of water bodies in the Luzhsky district of the Leningrad Region and the prospects for de-eutrophication. The monitoring data of water bodies were studied and the factors affecting the bioecological state of water bodies were considered.

\section{Research methods}

The study used physicochemical, sanitary-microbiological, parasitological and toxicological methods of research (Russian Standards 31861-2012, 2.1.5.980-00, 2.1.4.1110-02, 2.1.4.1175-02, 4.2.1884-04, 14.1:2:4.207-04).

Research objects:

- Obla River;

- Svinechnaya River;

- Toloni Lake;

- $\quad$ Lake Omchino.

The Leningrad Region is entirely located on the territory of the East European Plateau. This explains the flat nature of the terrain with insignificant absolute altitudes (mainly 50150 meters above sea level). The territory of the Karelian Isthmus (and especially its northwestern part) is characterized by rugged terrain, numerous rock outcrops and a large 
number of lakes. Geologically the Karelian Isthmus lies on the southern edge of the Baltic Shield's crystalline bedrock. The territory of the Karelian Isthmus, especially its northwestern part, is characterized by rugged relief, numerous rocky outcrops and a large number of lakes.

The highest point of the Karelian Isthmus is Mount Kivisyurya, $203 \mathrm{~m}$ above sea level, located not far from the village of Novozhilovo in the Kamennaya Gora tract.

The lowlands are mainly located on the shores of the Gulf of Finland and Lake Ladoga as well as in the valleys of large rivers. The main ones are Vyborg, Priozersk, Priladozhskiy, Predportovaya (seaside), Plyusskiy, Luga, the Volkhov, the Svir, and the Tikhvin.

The largest elevations are Lembolovsky, Izhora, Lodeynoye pole, Wasowska hills and Tikhvin ridge. The highest point of the region - Mount Gapselga (291 meters above sea level) - is located on the Veps hill. An interesting geographical feature is the Baltic-Ladoga ledge (glint) - a high (up to 40-60 meters) cliff that stretches for more than $200 \mathrm{~km}$ from the west to the east of the region. It is the shore of the ancient sea.

The territory of the region is located at the junction of two major tectonic structures.

The north-west of the region is located on the Baltic Crystal Shield, where Archean and Early Proterozoic rocks come to the surface. They were formed more than 600 million years ago as a result of powerful volcanic eruptions. Therefore, in this area, the main minerals are granite, facing stone and sand, and gravel material.

On the southern shores of the Gulf of Finland and Lake Ladoga, during the Cambrian period (about 500 million years ago), thick layers of sedimentary rocks (blue clays with sandstone layers) were formed.

Approximately 400 million years ago, during the Ordovician period, the formation of obolovye sandstones containing deposits of phosphorite and oil shale occurred (west of the region). In the south of the region, rocks of the Devonian period come to the surface.

In the eastern part of the region, rocks formed during the Carboniferous period are close to the surface. There are deposits of bauxite, limestone and dolomite.

Finally, the relief of the region was formed in the Quaternary period as a result of four glaciations and successive interglacial epochs. Therefore, in most of the region there are deposits of peat, clay and sand. The Leningrad Region has an extensive lake-river system that connects both the inner regions and the region with other regions and abroad. If we analyze the lake content within the Leningrad Region, the lake content of the Karelian Isthmus (the southern part of the Kola-Karelian geoblock of the Baltic Shield), excluding the water area of Lake Ladoga, will be about $10 \%$. As soon as the shield sinks under the East European plateau, the lacustrine content decreases and averages 1,5\% in the northwest of St. Petersburg, $2 \%$ in the southwestern part of the region, and 2,2\% in the east.

Toloni is a lake in the Luzhsky District of the Leningrad Region. The lake is located 2 $\mathrm{km}$ south of the town of Luga northwest of Lake Cheremenetsky. Toloni is a running lake - Intake is river Robotka, outtake is river Brewka. With an area of $0,6 \mathrm{~km}^{2}$, altitude above sea level of $36,8 \mathrm{~m}$.

Omchino is a lake in the Luzhsky District of the Leningrad Region. It is located on the north-western edge of the city of Luga. The height above sea level is $43,1 \mathrm{~m}$. The lake is divided into 2 reservoirs: Omchino itself (its southern part) and the so-called Shtollevskoe Lake, held by a dam through which the Obla River flows. Wetlands are found in the northern part of the lakes. The bottom relief is undulating covered with silty bottom sediments.

The Obla River is located in the south of the Leningrad Region. The mouth of the river is located $2 \mathrm{~km}$ along the left bank of the Vrevka River on the southern edge of Luga. The length of the river is $21 \mathrm{~km}$, the catchment area is $90 \mathrm{~km}^{2}$. The Svinechnaya River is similar to the Obla River in terms of hydrographic indicators $\square \square \square \square 6 \square$. 
According to the results of the analysis of the monitoring of the bio-ecological status of water bodies Luga river Region, rivers Obla, Svinechnaya, Omchino lake and lake Colony for the period from 2017 to 2020 we can draw the following conclusions.

When analyzing the data obtained, the results of 296 studies on physical and chemical indicators 48 studies on microbiological indicators and 16 studies on parasitological indicators were used.

When analyzing the data obtained, the results of 296 studies on physical and chemical parameters, 48 studies on microbiological indicators and 16 studies on parasitological studies were used.

According to quantitative chemical indicators such as hydrogen index, dissolved oxygen (not less than 4,0 $\mathrm{mg} / \mathrm{dm}^{3}$ ), BPK5 (no more than 4,0 $\mathrm{mg} \mathrm{O}_{2} / \mathrm{dm}^{3}$ ), chlorides, ammonium ion, nitrite ion, nitrate ion, total nitrogen, lead, cadmium, the water samples met the requirements of sanitary standards, with the exception of COD which in May-June exceeded the norm.

According to microbiological indicators, the presence of common coliform bacteria $(\mathrm{OKB})$ in the spring and summer period in the water of the Obla River and the Svinechnaya River exceeded the permissible norms by (no more than 500) an average of 2,3-6,2 times, in some cases by 21 times. The index of thermotolerant coliform bacteria (TCB) in the spring and summer period in the water of the Obla and Svinechnaya rivers exceeded the permissible norms by (no more than 100) an average of 4,8 times in some cases by 14 times. Microplastic particles are also periodically detected in these rivers (table). All this is a very unfavorable factor and indicates a strong pollution of these rivers.

Table 1. Pollution of the rivers Obla, Svinechnaya, lake Omchino (may - june 2019 g.).

\begin{tabular}{|c|c|c|c|c|c|c|}
\hline \multirow{2}{*}{ Indicator } & \multirow{2}{*}{ Unit rev. } & \multirow{2}{*}{$\begin{array}{c}\text { Hygienic } \\
\text { standard }\end{array}$} & \multicolumn{2}{|c|}{ r. Obla } & $\begin{array}{c}\text { r. } \\
\text { Svinechnaya }\end{array}$ & $\begin{array}{c}\text { I. } \\
\text { Omchino }\end{array}$ \\
\cline { 4 - 7 } & & $\begin{array}{c}\text { may } 2019 \\
\text { g. }\end{array}$ & $\begin{array}{c}\text { june } \\
2019 \mathrm{~g} .\end{array}$ & june 2019 g. & $\begin{array}{c}\text { june 2019 } \\
\text { g. }\end{array}$ \\
\hline $\begin{array}{c}\text { Ammonia } \\
\text { nitrogen }\end{array}$ & $\mathrm{mg} / \mathrm{kg} 3$ & $\begin{array}{c}\text { no more } \\
2.0\end{array}$ & - & - & - & 2.3 \\
\hline $\mathrm{OKB}$ & $\begin{array}{c}\mathrm{KOE} / 100 \\
\mathrm{ml}\end{array}$ & $\begin{array}{c}\text { no more } \\
500\end{array}$ & 700 & 1100 & 900 & 600 \\
\hline $\mathrm{TCB}$ & $\begin{array}{c}\mathrm{KOE} / 100 \\
\mathrm{ml}\end{array}$ & $\begin{array}{c}\text { no more } \\
100\end{array}$ & 130 & 250 & 200 & 120 \\
\hline
\end{tabular}

Currently, the world practice uses individual and complex indicators of chemical and physical pollution; complex biological indicators and mixed indicators. The method of individual indicators provides an accurate quantitative assessment of contamination with a specific substance. A significant disadvantage of using individual indicators is the inability to assess the state of the entire ecosystem as a whole. Integrated indicators are designed to assess the state of the entire aquatic environment. They are directly or indirectly related to many physical, chemical and even biological indicators, at least by the fact that they assess the state of the same water basin. These indicators more adequately reflect the state of the of aquatic object.

Complex indicators should be easy to use, universal, informative, physically and logically meaningful. Individual indicators assess the contamination of water with a specific substance at a specific time, and the actual concentration of the pollutant is compared with the MPC. In the practice of environmental and water management assessment the biochemical oxygen consumption (BOD) is used as an individual indicator. Moreover, this indicator is more often used only to assess water pollution with organic substances. However, this indicator is related to the saprobity index (which takes into account the ability of a hydrobiont community to withstand a specific level of organic pollution) and the Shannon index (which takes into account the total number of living 
organisms and their species diversity).

Complex indicators include:

- ICP - an indicator of chemical pollution, determined by 10 indicators;

- combinatorial pollution index B considering the frequency of occurrence of contamination (assesses - relative water pollution);

- indicator Erismann F. - assessing the water quality groups limiting indicator of harm (health, organoleptic, sanitary-Toxicological, epidemiological);

- ecotoxicological criteria Moiseenko T. - defines the total indicators of toxicity, physicochemical contaminations, metroplasty (the concentration of phosphorus). Allows you to take into account the background concentrations of pollutants, but does not take into account the significance of each category for a water basin;

- a comprehensive assessment for G. Frumin and L. Barkan - for a specific pollutant based on the results of the calculation of the Harrington desirability function. This indicator takes into account the significance of each pollutant, but is not sensitive to high concentrations and close to background concentrations;

- IZV and its modifications-the water pollution index determined by 5-7 indicators is easy to determine allows you to use the existing database according to the State Water Cadastre, and gives comparable results for different objects.

Disadvantages - the use of a fixed set of pollutants, the need to choose substitutes for MPC for dissolved oxygen, temperature and $\mathrm{pH}$; does not take into account the hydrological characteristics of the object; can not be used to predict water quality in water management practice. In general, physical and chemical methods are easy to use, and therefore are used in engineering practice. But due to the need to select only some pollutants from a very large number of them, the subjectivity of the assessment of the studied water basin arises. Bioindication methods are usually simpler and cheaper than chemical analysis and allow you to get an integral assessment of the state of the reservoir based on the state of aquatic objects. The following indices are used most often for biological assessment: saprobity, stability, species diversity, oligochaete and biotic. With all the simplicity of application biological methods are not very applicable for water management practice. They are not very reliable for large ecosystems and have no clear connection with the hydrochemical parameters of the aquatic environment CCB [7-9].

When studying these water basins, the following violations were noted: in the water protection zone along the banks you can see accumulations of solid household waste which lead to a violation of the ecosystem of reservoirs. Observed the destruction of river banks thereby flushing solids in water which contributes to increased water turbidity in connection with a reduction in the depth of light penetration, leading to inhibition of photosynthesis underwater vegetation.

The process of eutrophication has the following basic stages:

In the upper layer of water, there is a concentration of nutrients, which provokes the active development of microflora (primarily phytoplankton, also algae-fouling) in this zone and an increase in the mass of zooplankton feeding on phytoplankton. Such growth reduces the transparency of the water, the depth of penetration of the sun's rays decreases, as a result of the lack of light, the death of bottom plants begins. The process of dying off of bottom water plants entails the death of other organisms that these plants form a habitat for or for which they are a higher link in the food chain.

The activity of increasing the biomass of plants (especially algae) depends on the temperature regime of the upper water layer. At night, photosynthesis in these plants does not occur, but the active process of respiration continues. In the summer in the pre-morning hours of warm days the oxygen content in the upper water horizons decreases and the death of aerobic organisms inhabiting these horizons and demanding oxygen content is observed (the so-called "summer zamor"). 
Dead organisms fall to the bottom of the reservoir and are decomposed by aerobic bacteria. However, the hypoxic bottom vegetation is no longer able to provide adequate oxygen production. And if we take into account that the total bio-productivity of the eutrophic reservoir increases, the imbalance between the production and consumption of oxygen in the bottom horizons increases. The aggravated lack of oxygen leads to the death of the oxygen-demanding bottom and bottom fauna. A similar phenomenon is observed in winter in shallow closed reservoirs - the so-called "winter zamor".

In the bottom soil, deprived of oxygen, there is an anaerobic decomposition of dead organisms with the formation of such strong poisons as phenols and hydrogen sulfide, and such a powerful "greenhouse gas" (in its effect in this regard exceeding carbon dioxide by 25 times) as methane. As a result, the process of eutrophication destroys most of the species of flora and fauna of the reservoir almost completely destroying or very much transforming its ecosystems, and greatly worsens the sanitary and hygienic quality of water up to its complete unsuitability for bathing and drinking water supply. The reservoir can even become a swamp due to low oxygen levels.

The main anthropogenic sources of phosphorus and nitrogen are untreated wastewater (especially from livestock farms) and the flushing of fertilizers from fields.

Since the early 2010-s, EU countries have gradually introduced restrictions on the use of phosphates in household washing powders at a level of no more than $0,3-0,5$ grams of phosphorus per wash cycle.

In recent decades, due to the increased anthropogenic impact, the intensity of eutrophication has increased dramatically. Accelerated, or so-called anthropogenic eutrophication is associated with the entry into water bodies of a significant amount of nutrients-nitrogen, phosphorus and other elements in the form of fertilizers, detergents, animal waste, atmospheric aerosols, etc. In modern conditions, eutrophication of water bodies occurs in a much shorter period of time - several decades or less. The processes of anthropogenic eutrophication cover not only the major lakes of the world, but also Lake Ladoga. In the Luzhsky district this primarily applies to the Omchino and Toloni lakes.

To combat eutrophication of water bodies preventive and regulatory measures are used.

Preventive measures provide for the complete cessation of the discharge of untreated and conditionally treated wastewater from industrial enterprises and domestic wastewater into the reservoir. The practical implementation of preventive measures is a complex, longterm, capital-intensive process and is associated with the expansion of new technical and biological problems.

The main measure to prevent eutrophication of water bodies is to protect them from excessive intake of chemical pollutants, in particular phosphorus and nitrogen. This is achieved in the following ways. First of all, they include increasing the culture of agriculture. For this, it is necessary to minimize the amount of nutrient runoff from agricultural land It is recommended not to use increased doses of fertilizers.

Another measure is the interception of biogens removed from agricultural land. For small reservoirs, it is most appropriate to construct an annular drainage system with the subsequent removal of collected wastewater outside the catchment area. In the case of large bodies of water, it is necessary to intercept the biogens coming through the hydrographic network - the main route of surface runoff.

Regulatory measures include physical (artificial mechanical cleaning and aeration), chemical and biotechnological methods.

It is quite possible to introduce various drugs into the reservoir that suppress the primary production. However, this method is very vulnerable since drugs that inhibit photosynthesis are more or less toxic to invertebrates and fish.

Physical effects are reduced to the dilution eutrophierung water clear waters. This leads to an increase in their transparency. Good results are obtained by aeration of water in the 
prevention of eutrophication of small reservoirs. In most cases, aeration plants operate on the principle of supplying air to the reservoir (laying air supply perforated pipes in the bottom layer). You can also use water spraying in the atmosphere (gushing). With the improvement of the oxygen regime, the mineralization of organic matter increases, its accumulation in the reservoir decreases or stops.

A promising method is cavitation that is exposure to water bodies by ultrasound which causes the appearance of bubbles with a vapor-gas mixture in the liquid. The rupture of the bubbles is accompanied by the destruction of the algae cells. This method was tested in Lake Ladoga.

The most promising is the prevention of eutrophication by biotechnological methods. Back in 1932, the Russian scientist E. E. Uspensky proposed to prevent the development of algae with the help of macrophytes that intercept biogens coming from the catchment area in the coastal strip $\square 10 \square$. At the same time, it is necessary to exercise strict control over the withdrawal of phytomass of macrophytes. Otherwise, after their death the biogens will again be in the water, not to mention the negative effect of the process of rotting macrophytes in the coastal area.

It is very advisable to cultivate wild rice (Zizania aquatica), beckmania (Beckmania niasyzigachne) and canary (Phalaris aquatica) in the coastal area which give a large percentage of phytomass with high feed qualities of $\square 11,12 \square$. Cultivation of these plants with their subsequent harvesting is not only an effective measure to combat eutrophication, but also an additional way to strengthen the feed base of animal husbandry.

The initial selection of Chlorella vulgaris BIN is recommended for the strain of Chlorella vulgaris IGF № C-111 which was cultivated on wastewater from domestic, industrial and agricultural enterprises. As a result, the strain which is the most adapted and not demanding to the cultivation conditions was selected $\square \square \square \square 15 \square$.

Chlorella does not require the presence of carbon dioxide in the nutrient medium. This made it possible to create a fundamentally new biotechnology for growing microalgae. A modular installation was developed which is successfully used in livestock farms and in cultivation workshops. Cylindrical glass tubes with lamps permanently placed in them are installed vertically in a special container.

Fans are installed under the glass pipes which can be supplied with air when the suspension temperature is reached exceeding the optimal temperature for the cultivation of chlorella. Inside the container there is a suspension temperature sensor which is connected to a temperature controller connected to the fans. The plant is capable of producing 160 liters of chlorella suspension per day with the ability to increase the number of installations depending on the required amount of suspension.

It is also very promising to use herbivorous fish to combat eutrophication of water bodies. Along with the prevention of eutrophication currently, in many countries, efforts are being made to deeutrophication reservoirs. For this purpose, water is partially or completely replaced, bottom sediments are removed, hypolimnion and upper soil layers are aerated, water mass is destratified and biogens are bound and deposited.

The introduction of the algolizant Chlorella vulgaris should be carried out when the water temperature in the lower layers of the reservoir reaches $+5-10{ }^{\circ} \mathrm{C}$ and repeat after 23 weeks. At the same time, in winter when ice is frozen, ice is cleared from snow from $1 / 3$ to $50 \%$ of the reservoir area, in the absence of ice in winter and in spring hydro-mechanical aeration of the reservoir is carried out at intervals of 2-3 weeks.

The algolizant is added to the reservoir in the amount of 15-25 liters per $1 \mathrm{~m}^{3}$ of water in the deep part and 15-25 liters/ha in the shallow part of the reservoir with a depth of no more than $5 \mathrm{~m}$. The introduction of algolizant and hydro-mechanical aeration in the spring period is carried out simultaneously. The suspension of Chlorella vulgaris before entering the reservoir is cooled from the cultivation temperature to the water temperature in the 
lower layers of the reservoir $5-10{ }^{\circ} \mathrm{C}$ and kept for 1,5-2 days. Cleaning of ice from snow and hydro-mechanical aeration is carried out in the shallow part of the reservoir with a depth of no more than $5 \mathrm{~m}$.

Aeration can be carried out, for example, using the floating installation " $\mathrm{H}_{2} \mathrm{O}-\mathrm{IAB}$ ". The installation consists of any floating means on which the jet-vortex aerator "SVIL" is installed. This aerator contains a housing, a mixing chamber, a perforated diaphragm with devices for twisting the water flow and vortex chambers, a collector with an air supply pipe. In the mixing chamber there are pipes of variable cross-section with holes.

At the entrances of the pipelines, ejectors connected to the collector are installed and at the outlet of the mixing chamber, a device is installed to give turbulence to the flow.

Water from the reservoir is fed through a pressure pipe to the aerator to a perforated diaphragm, passes through a device for twisting the water flow and ejectors. Due to the formation of a rarefied zone in the devices air flows from the collector through the tubes. The mixing process begins in the vortex chamber and continues in the mixing chamber in which a rotational motion is created.

This water-air mixture coming from the chamber and pipelines is suspended. The additional enhanced rotational motion significantly increases the effect of mixing and dissolving the water-air mixture with water masses.

To combat blue-green algae, it is most appropriate to use the biotechnological method of algolization - the introduction of a single-celled green algae-chlorella which shows antagonism to blue-green algae. It is most advisable to carry out algolization in winter with a suspension of Chlorella vulgaris.

To preserve the bioecological state of water bodies, a set of measures is necessary to control and protect the water protection zone of these objects to control the discharge of wastewater into river water bodies and to prevent landfills on these water bodies.

The Luga District has established a Public Advisory Council for the Luga River Basin, where heads of local settlements, educational and public organizations as well as representatives of the media and fishing clubs actively participate. The Round Table "The quality of natural waters in the Luga River Basin: public participation in identifying and solving water problems" is held periodically. During the event, the main environmental problems in the river basin are discussed as well as field trips to study the water quality in the water bodies of the Luzhsky district. The organizers of these events are "Ecocentrum" LLC and "Friends of the Baltic" REOO within the framework of the Barents-Baltic program "Nature and Man".

\section{Conclusions and recommendations}

1. It has been established that the process of eutrophication of the water basin of the Luga district of the Leningrad region is due to certain objective and subjective reasons: transformation of coastal and bottom ecosystems due to methanolysis of natural and bottom fauna and oxygen deficiency in water bodies; the presence of anthropogenic sources of phosphorus and nitrogen in untreated wastewater; lack of ring drainage systems that prevent runoff from agricultural land near water bodies; the absence in the Russian Federation of directive documents restricting the use of phosphorus and nitrogen compounds in detergents and cleaning industrial and household products; lack of understanding and eco-culture among many business leaders who allow the discharge of hazardous industrial wastewater into water bodies in violation of Art. 58 and 72 of the Basic Law of the Russian Federation.

2. To recommend to the Government of the Russian Federation to consider the issue of Russia's accession to the Convention of the Baltic States on limiting the use of phosphorus and nitrogen compounds in the production and use of detergents and cleaning agents. 
3. To involve the general public of the Luga region in identifying and solving problems and tasks of de-eutrophication of water bodies in the region.

\section{References}

1. M. Zalewski, M. McClain, S. Eslamian, Ecohydrology - the background for the integrative sustainability science, 71-73 (2016) doi: 10.1016 / j.ecohyd. 2016. 04.003

2. M. Le Moal, G. Pinay, Ch. Gascuel-Odoux, The Science of the Total Environment 1, 1-11 (2019) doi: 10.1016 / j.scitotenv. 2018. 09. 139

3. Zh. Shen, J. Niu, Y. Wang, Advanced topics and technology in China, 161-177 (2013)

4. V. Sboychakov, L. Kletsko, Prenosology and Healthy Lifestyle 2, 62-67 (2020)

5. Luga, https://ru.wikipedia.org/wiki

6. Luga, https://docviewer/yandex.ru.Brochure_for_inhabitants.pdf

7. A. Godoy Cottas, E. Julio Ribeiro, W. Rosa Cunha, Industrial Biotechnology 2, 45-49 (2020) doi:10.1089/ind. 2019. 29196

8. Haiming Wu, Guangzhu Shen, Li Lin, RSC advances 7, 18421-18427 (2017)

9. A.K. Stewart, R. Ravindra, R.M. Van Wagoner, J. Natural Products (Lloydia) 2, 349355 (2018) doi:10.1021/acs. J natprod.7b00829

10. E. Uspensky, Physical and chemical environmental conditions as the basis of microbiological processes (1963)

11. Zizania, The Plant List, http://www. theplantlist.org/browse/A/Poaceae/Zizania

12. Zizania aquatica L., U.S. National Plant Germplasm System, https://npgsweb.arsgrin.gov/ gringlobal/taxonomydetail.aspx?42267

13. A. Zagareanu, Stiinta agricola 1, 78-83 (2013).

14. Yi Li, Zhiyu Zhang, Yingxing Duan, Bioresource Technol. 280, 188-198 (2019) doi:10.1016/j.biortech.2019.05.28

15. L.A. Robertson, Trends in Microbiology 9, 353 (1998) 